\title{
Modernization of therapy in patients with chronic obstructive pulmonary disease and ischemic heart disease
}

During the combination treatment of chronic obstructive pulmonary disease in association with ischemic heart disease, the increasing attention is paid to pleiotropic effects of statins. Inclusion of rosuvastatin in the treatment regimen allows reducing and stabilizing the main clinical manifestations of this disease constellation, improving the quality of life.

\section{KEYWORDS: Chronic obstructive pulmonary disease, comorbidity, rosuvastatin, pleiotropic effect}

\section{Introduction}

Today doctors are increasingly facing the socalled comorbid course of chronic obstructive pulmonary disease (COPD) and ischemic heart disease (IHD), which is accompanied with the syndrome of mutual burdening and development of the "vicious circle", which leads to deterioration of COPD and has a negative impact on the effectiveness of basic treatment [1-3]. Taking into account these circumstances, the considerable attention is paid to treatment of co-morbidities in the international consensuses and protocol of patients with COPD $[4,5]$.

Most confirmed hypotheses consist in the fact that in such an association diseases are connected with common risk factors (active or passive smoking, adverse environmental conditions, respiratory tract infections) which cause chronic systemic inflammation by acting on vascular endothelial cells, airway epithelium, lung parenchyma [6].

The use of basic medications for the treatment of COPD, such as inhaled corticosteroids, has a pronounced anti-inflammatory effect on both the local and systemic levels, and it does not ensure the complete elimination of inflammation $[3,7]$.

Taking into account the common risk factors and pathogenetic mechanisms in development of both diseases, increasing attention has been paid to the use of statins in treatment of COPD. This group of medications except the main one - of lipid-lowering action, has pleiotropic (anti-inflammatory, immunomodulatory, and antioxidant) effects, influencing not only the condition of the vascular wall, but also the diseases of respiratory system $[2,4]$. Under the influence of statins, a decrease in the level of systemic inflammation markers and C-reactive protein (CRP) occurs, by means of reducing the production of interleukin-6 [1].

The results of randomized multicenter studies demonstrated that statin therapy in high doses reduces the risk of mortality in patients with COPD, decreases exacerbations and slows the processes of emphysema development $[8,9]$.

Thus, the use of statins in treatment of COPD combined with ischemic heart disease requires further study.

The aim of the research is to investigate the clinical efficacy of the use of rosuvastatin in treatment of COPD combined with ischemic heart disease.

\section{Materials and Methods}

We examined 30 patients with COPD of B group combined with ischemic heart disease (stable exertional angina of FC II) aged from 51 to 67 (average age was $57.03 \pm 3.51$ ) who were hospitalized in the Pulmonology Department of Poltava regional clinical hospital named after Sklifosovsky. The average duration of COPD in examined patients was between 10 and 15 years.

The diagnosis of COPD was established in accordance with the order of the Ministry of Public Health of Ukraine No 555 as of 06.27.2013 [10] and the provisions set forth in the document GOLD (Global Initiative for Chronic Obstructive Lung Disease) [11]. IHD diagnosis was verified on the basis of clinical
Vyacheslav Zhdan, Galina Khaymenova*, Lyudmila Shilkina, Maksim Potyazhenko, Daria Martynyuk \& Elena Kiriyan

Ukrainian Medical Stomatological Academy, Poltava, Ukraine

*Author for correspondence: g_haymenova@mail.ru 
picture, medical history, ECG, and a six-minute walk test (SMWT) [12].

According to the aim of the study, all patients were divided into two groups. Patients were selected based on the "case-control" method, so that the groups were comparable in terms of age, $\mathrm{COPD}$ group, $\mathrm{FC}$ of stable angina.

Patients of the main groups $(\mathrm{n}=15)$ received COPD protocol therapy, namely $25 \mu \mathrm{g}$ of serevent by two inhalations twice a day; if necessary, $0.4 \mathrm{~g}$ of aerofillin twice a day, $0.3 \mathrm{~g}$ of ambroxol twice a day. The protocol treatment of IHD included isosorbide- dinitrate at a dose of $20-40 \mathrm{mg} /$ day, cardiomagnil at a dose of 75 $\mathrm{mg} /$ day, $10 \mathrm{mg}$ of rosuvastatin. Patients of the control group $(\mathrm{n}=15)$ did not take rosuvastatin.

Patients were examined before and 12 days after treatment, therapy included the assessment of respiratory symptoms on a scale from 0 (no symptoms) to 3 (considerably severe symptoms). The degree of dyspnea was assessed using a modified scale of dyspnea (shortness of breath), MRC (Medical Research Counsil Dyspnoea Scale) [13]. Exercise tolerance was studied by a six-minute walk test (SMWT), which was conducted according to standard procedures.

The distance that a patient covers over the period 6 minutes was taken into account. The level of cholesterol, LDL, HDL was determined. The respiratory function was defined: FEV 1 (forced expiratory volume in the 1st second), FEV1/FVC - Gaensler index (GI), Tiffeneau index modification FEV1/VC [14].

The average frequency of exacerbations during the previous year has been evaluated by a retrospective study of medical history.

Statistical analysis was performed using Excel 7.0 editor. The results are given in the tables as the arithmetic average \pm standard deviation ( $\mathrm{M}$ $\pm \mathrm{m})$ [15]. In order to evaluate the differences in performance as compared with the original data, Student's t-test was used. A significant difference was considered with the error probability $\mathrm{p}<0.05$.

\section{Results}

After the treatment of patients in both groups, the improvement in clinical status was detected due to decreased severity of respiratory symptoms: cough, sputum, dyspnea, as well as increased exercise tolerance and improved laboratory and instrumental performance.

A. One of the patients, 54 years old, was admitted for inpatient treatment in pulmonology department of the Poltava Regional Clinical Hospital Sklifosovsky 05.15.16, complaining of periodical fever up to $37.5^{\circ} \mathrm{C}$, usually in the evening, cough with sputum, significant shortness of breath, general weakness, marks a low exercise capacity, fatigue, lack of appetite, periodically arising heartaches [16].

\section{- Objectively}

General state of moderate severity. In the lungs - vesicular breathing weakened. Heart rate96 beats per 1 mininutu, blood pressure-150/90 $\mathrm{mm}$ hg. art. Abdomen soft, painless, the liver does not protrude from under the edge of the costal arch, the ECG left ventricular hypertrophy, diffuse violation of repolarization.

\section{- The entering diagnosis}

Chronic obstructive pulmonary disease combined with coronary heart disease. Patients were conducted comprehensive clinical and diagnostic examinations: blood tests, kidney tests, liver function tests - bilirubin, AST, ALT, total protein; coagulation, electrolytes, lipids, urinalysis, ECG, Echo-KS, abdominal ultrasound. Estimation of respiratory symptoms in points, exercise tolerance, external respiration function evaluation cholesterol, low density lipoproteins (LDL) and high density (HDL) lipoproteins.

After a thorough examination and diagnosis of COPD was assigned protocol therapy, namely: Serevent $25 \mathrm{mcg}$ two inhalations twice a day, if necessary Aerofillin $0.4 \mathrm{~g}$ twice a day, ambroxol $0.3 \mathrm{~g}$ twice a day and treatment protocol CHD comprising isosorbide dinitrate $20-40 \mathrm{mg} /$ day, cardiomagnil $75 \mathrm{mg} /$ day, $10 \mathrm{mg}$ of rosuvastatin.

12 days after the treatment is carried out the repeated set of laboratory, clinical and instrumental studies: evaluation of respiratory symptoms in scores, exercise capacity, lung function, assessment of the level of cholesterol, low density lipoprotein and high-density lipoprotein.

After the treatment, the patient showed improvement of clinical condition by reducing the intensity of the severity of respiratory symptoms: cough, sputum, dyspnea and increase exercise tolerance and improve laboratory and instrumental performance (TABLE 1).

It was noted that regression of the respiratory symptoms in the main group of patients was more manifested in the comparative analysis of clinical symptoms between the groups. Thus, 
Table 1. Clinical and instrumental indicators in patients with COPD of B group in the combination with IHD, FC II.

\begin{tabular}{|c|c|c|c|c|}
\hline \multirow{2}{*}{ Indicators } & \multicolumn{2}{|c|}{ The I group (main) } & \multicolumn{2}{c|}{ Group II (control) } \\
\hline Cough (scores) & Before treatment & After treatment & Before treatment & After treatment \\
\hline Sputum (scores) & $2.2 \pm 0.13$ & $1.75 \pm 0.05^{*} \#$ & $2.3 \pm 0.13$ & $1.9 \pm 0.06^{*}$ \\
\hline Breathlessness (scores) & $2.32 \pm 0.17$ & $1.61 \pm 0.06^{*} \#$ & $2.4 \pm 0.16$ & $1.78 \pm 0.07^{*}$ \\
\hline $6-$ minute test $(m)$ & $2.33 \pm 0.12$ & $1.83 \pm 0.10^{*}$ & $2.27 \pm 0.11$ & $1.82 \pm 0.10^{*}$ \\
\hline FEV $\%$ & $511.47 \pm 20.57$ & $467.17 \pm 19.35^{*}$ & $409.20 \pm 20.46$ & $453.47 \pm 18.58$ \\
\hline$G l$ & $62.7 \pm 3.76$ & $65.57 \pm 3.27^{*}$ & $55.51 \pm 2.98$ & $62.8 \pm 3.02$ \\
\hline$*(p<0.05-p<0.001)$ significant difference of indicators in the dynamics of treatment; & $72.1 \pm 3.61^{*}$ & & $70.26 \pm 3.51$ \\
\hline \# $(p<0.05)$ significant difference of indicators between the groups after treatment. & & \\
\hline
\end{tabular}

\section{Table 2. Lipid profile indicators in patients with COPD of B group in the combination with IHD, FC II.}

\begin{tabular}{|c|c|c|c|c|}
\hline \multirow{2}{*}{ Lipid profile indicators } & \multicolumn{2}{|c|}{ The I group (main) } & \multicolumn{2}{c|}{ Group II (control) } \\
\hline & Before treatment & After treatment & Before treatment & After treatment \\
\hline Cholesterol & $5.88 \pm 0.35$ & $4.20 \pm 0.25^{*} \#$ & $5.77 \pm 0.35$ & $2.75 \pm 0.35$ \\
\hline Triacylglycerol & $2.17 \pm 0.11$ & $1.68 \pm 0.08^{*} \#$ & $2.14 \pm 0.11$ & $3.23 \pm 0.19$ \\
\hline LDL & $3.38 \pm 0.20$ & $2.43 \pm 0.15^{*} \#$ & $3.25 \pm 0.20$ & $1.05 \pm 0.05$ \\
\hline $\mathrm{HDL}$ & $0.95 \pm 0.05$ & $1.16 \pm 0.06^{*}$ & $1.06 \pm 0.05$ & \\
\hline$*(p<0.01-p<0.001)$ significant difference of indicators in the dynamics of treatment; & & \\
$\#(p<0.001)$ significant difference of indicators between the groups after treatment. &
\end{tabular}

the patients of the main group had statistically significant decrease in the intensity of cough and quantity of sputum than patients in the control group $(\mathrm{p}<0.05)$.

Furthermore, the pattern has been observed in the analysis of tolerance to physical activity between these groups of patients. After treatment patients had the increased tolerance to physical activity, but the patients of group II did not have a substantial nature of this condition, whereas the patients of the main group had significantly higher index $(\mathrm{p}<0.05)$.

It should be noted that in patients of the main group after treatment there was significant reduction of wheezing by means of increased FEV1 and GI $(\mathrm{p}<0.05)$.

Having analyzed the lipid levels in patients from the main and control groups before and after treatment, the significant difference was observed. Thus, after treatment in patients of the main group, as one can see from TABLE 2, there was a significant reduction in blood levels of total cholesterol, triglycerides, LDL and increase in HDL ( $\mathrm{p}<0.01)$ (TABLE 2).

The retrospective study of the case history $(1.6 \pm 0.48)$ revealed that the frequency of exacerbations in the past year was observed from 1 to 2 times per year.

\section{Conclusions}

1. Inclusion of rosuvastatin in the comprehensive treatment of patients with COPD in combination with IHD can reduce and stabilize the main clinical manifestation of this constellation of diseases through its pleiotropic action.

2. The frequency of exacerbations of COPD in patients with cardiovascular pathology with the use of statins is significantly reduced; thereby the quality of patients life is improved.

\section{REFERENCES}

Eduard W, Pearce N, Douwes J. Chronic bronchitis, COPD, and lung function in farmers: the role of biological agents. Chest. 136(3), 716-725 (2009).

Blanc PD, Iribarren C, Trupin L et. al. Occupational exposures and the risk of COPD: dusty trades revisited. Thorax. 64(1), 6-12 (2009).

Potyazhenko M, Approach LN, Access LN et. al. Modern methods of treatment of coronary heart HSEEU “UMSA.” -Poltava: OOO
“Company” Techservice “. 103 (2016).

Pristupa LN, Murenets A, Dominas VM, Kirichenko NN. Klinicheskaya i protivovospalitel'naya effektivnost' primeneniye atorvastatina v kompleksnom lechenii bol'nykh khronicheskim obstruktivnym zabolevaniyem legkikh. Zhurnal klinichnikh ta yeksperimental'nikh medichnikh doslidzhen. 4(5), 461-465 (2013).

Vakhnenko AV. Sovremennyye podkhody lecheniya khronicheskoy obstruktivnoy bolezni legkikh s soputstvuyushchey khronicheskoy serdechnoy nedostatochnost'yu. Svit meditsini ta biologiie
3, 70-73 (2014).

Samorukova YeI, Zadionchenko VS, Adasheva TV, Malinicheva YUV, Sinkin MV. Pleyotropnyye effekty rozuvastatina u bol'nykh khronicheskoy obstruktivnoy bolezn'yu legkikh. Lechashchiy vrach. 7, 103-107 (2015).

ESC/EAS Guidelines for the management of dyslipidaemias: the Task Force for the management of dys-lipidaemias of the European Society of Cardiology (ESC) and the European Atherosclerosis Society (EAS). Eur Heart J. 32(14), 1769-1818 (2014). 
Jerwood S, Cohen J. Unexpected antimicrobial effect of statins. J Antimicrob Chemother. 61(12), 362-364 (2014).

Cholesterol Treatment Trialists' (CTT) Collaboration. Efficacy and safety of more intensive lowering of LDL cholesterol: a metaanalysis of data from 170,000 participants in 26 randomised trials. Lancet. 376, 1670-1681 (2015).

$\mathrm{MOH}$. Standardization of care in chronic obstructive pulmonary disease.

Lu M, Yao W Z. Asthma and chronic obstructive pulmonary disease overlap syndrome: An update. J Transl Int Med. 3(4), 144-146. (2015).

Sidorenko GI, Frolov AV, Komissarov SM. Diagnosis serdechnoy nedostatochnosti (New kolichestvepbe podhodb). Cardiology in Belorussii. 4(5), 24-28 (2009).

Feshtenko YUI. Redrafted globalynoy initsiativb in HOZL. Ukrainsykiy pulymonologychniy journal. 2, 6-8 (2012).

Struchkov PV. Spirometry rukovodstvo dlya Vrachesh. GIOTAR-Media. (2016).

Khaymenova GS. Modern approach to prevention and treatment of exacerbations of COPD patients in combination with osteoarthritis. J Ukrainian Med Dental Ac. 2 (54), 192-195 (2016).

Khaymenova GS, Shilkina LN , Babanina MY , Volchenko GV, Tkachenko MV, Zhdan VN. Evaluating the effectiveness of treatment of patients with both COPD and osteoarthritis over. WiadomostiLekarskie - Konstancinezorna (Poland), Tom LXIH, nr 2 (cz.II). C.214-218 (2016) 